\title{
Research of Learning Scoring Model for Chinese Police Information Management Course
}

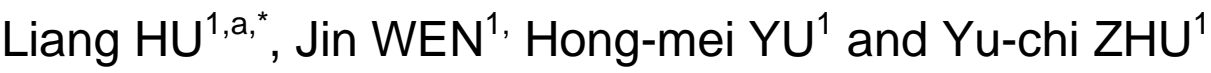 \\ ${ }^{1}$ Department of humanities and management, JiangXi Police College \\ NanChang, China \\ ahuliang_thu@163.com
}

Keywords: Learning scoring, Police information management, Course, Analytic hierarchy process.

\begin{abstract}
This research analyzes the key factors of the learning quality index and the teaching effect of Chinese police information management course and proposes a learning scoring model. The model uses the analytic hierarchy process to compute the weight of each factor index, establishes the index weight coefficient by a scientific system of evaluation matrix of data analysis collected the survey sampling mode, and then according to the data analysis gives a comprehensive evaluation score of students' study.
\end{abstract}

\section{Introduction}

Police information management is a highly applied subject, the combination of computer and modern communication technology is the main symbol of modern public security information technology. Police information management is not only an important field of management science, but also an important branch of information science[1][2]. Through the course of police information management for the students of police administration in police colleges and universities, we should cultivate a group of talents who have both the knowledge and skills of public security, and the ability to use information in the process of police information [3].

Evaluation of the quality and effect of learning of police information management course are given by using a general qualitative or simple evaluation opinion. But because the evaluation content involves the deviation and subjective reasons and standard, the evaluation result is discreteness and influences its comprehensive evaluation conclusion. With the popularization of quantitative research methods, the mathematical relationship between the use of mathematical methods for the evaluation index and the teaching quality and effect of the establishment of evaluation system, evaluation method can determine a scientific, reasonable, qualitative and quantitative analysis to improve the accuracy and reliability of the comprehensive evaluation[4][5][6]

On the basis of quantitative research, this paper introduces the analytic hierarchy process to compute the weight coefficient of learning evaluation index, and establishes the comprehensive evaluation model. 


\section{Learning SCORING Model}

The key to the establishment of learning scoring model for Chinese police information management course is to quantify the weight coefficient of evaluation index. In this study, the analytic hierarchy process (AHP) is used to solve the weight coefficient. AHP is not put all the factors to compare together, but only compares two factors with the same scale, which can reduce the factors of different properties are compared with each other in trouble, so as to improve the accuracy of quantitative evaluation.

1) Establish a hierarchical structure. According to the analysis of main factors of network curriculum and evaluation index, based on the principles of the evaluation index, analysis the correlation between the basic properties and the indexes of the evaluation of teaching quality and effect and affiliation, use of learning evaluation model of Delphy method to build learning evaluation index elements[7].

Course Content: For the public security, the course content of public security colleges should reflect the teaching idea that teaching content can be shown to support independent and gradual learning, and fully demonstrate learning content of training applied talents of public security target.

Course Form: The course of public security information management is to serve the teaching content, and to provide independent and progressive learning by means of rich graphics, images, animation and so on[8]. According to the different teaching characteristics of the media, according to the different teaching characteristics of the media, it is necessary to choose the appropriate forms of media expression. This can not only give full play to the advantages of media resources and achieve good teaching results, but also pay attention to the application of media resources to maximize the effectiveness of the problem.

Instructional Design: The instructional design method based on the combination of theory and application is the main line of the whole curriculum connotation construction[9][10]. Under the guidance of instructional design, learners are able to carry out autonomous and cooperative learning by chapter by day, step by step, step by step. Teaching design should be able to generate interest and desire to learn to support the learners to learn.

Multimedia Application Value: Public security information management course provides multimedia information resources that is to understand the problem to solve the difficult and important contents in the network courses, through the vivid description of multimedia information resources, is conducive to learning.

Multimedia Application Effect: In the course of multimedia expression form to the difficulty and the key question explanation is correct, the expression way is accurate, produces the image description not to be able to present the image, intuitive, clear application effect.

Knowledge Development: Focus on learning the construction goal of the importance of learning security problems of network course difficult and key issues, provide the expansion of knowledge through the link and hotkeys, reinforcement learning to understand the difficulties and focus of knowledge.

Learning Type: To create a learning environment for collaborative learning, that is, the establishment of collaborative learning platform, the design of collaborative learning related exercises and assignments. Through the network curriculum independent + 
collaborative learning, improve the learning interest and learning desire, enhance learning ability, further cultivate learners of related knowledge, information retrieval, analysis, induction and processing ability.

Learning Resource Sharing: To solve the problem of sharing information resources in the form of curriculum management platform, such as learners' learning outcomes, training reports and so on.

Interactive Function: The first is the interaction between teachers and students, teachers through the network curriculum management platform of the message board layout, individual and collective $\mathrm{Q} \& \mathrm{~A}$; followed by the exchange of learning and communication between learners;

Learning Convenience: Network courses are not affected by the time and place of study.

Learning Navigation: The course provides a convenient learning navigation system that is able to quickly jump to the desired page and related link information resources according to the learner's needs. At the same time, it also provides quick query function.

Supporting Teaching Resources: The course of public security information management is related to the electronic reference books, electronic journals, multimedia teaching resources and other teaching resources.

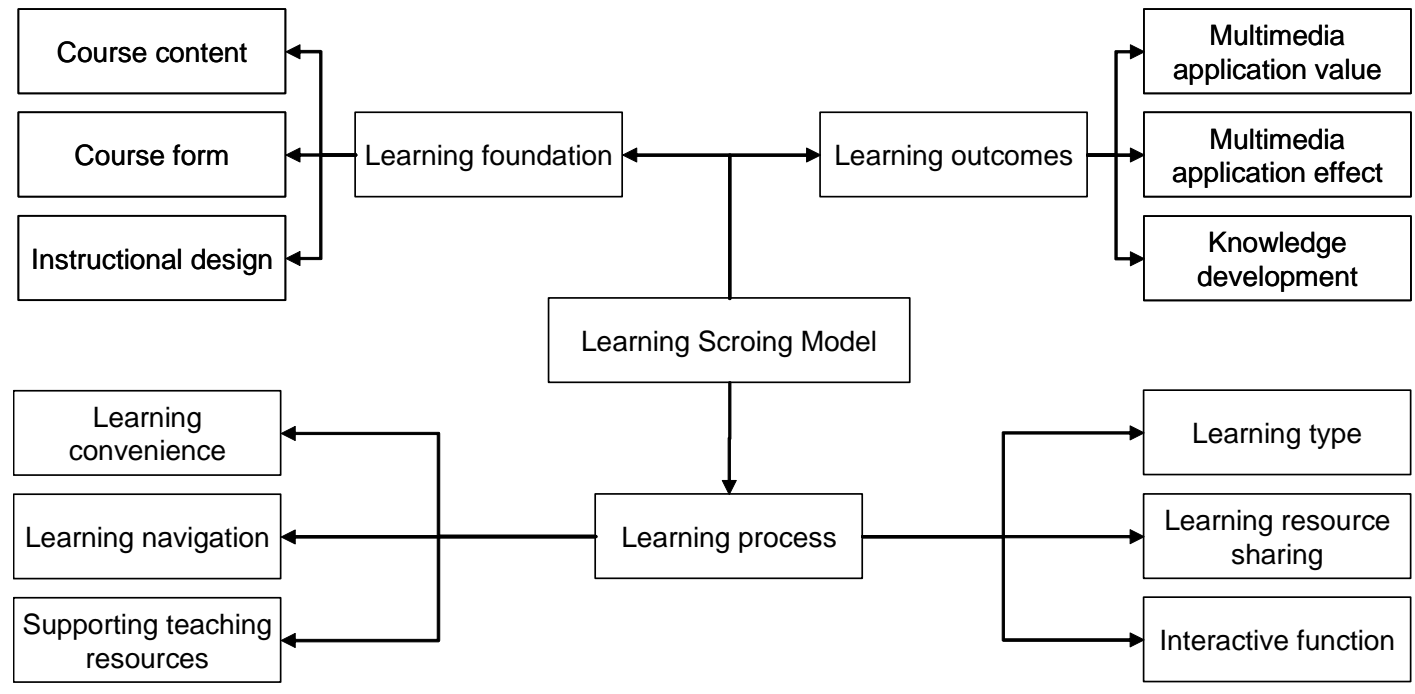

Figure 1. Index system of learning scoring model for police management course

2) Set up a judgment matrix. Invite professional teachers and managers and other professionals, according to the target layer of the relative importance of each criterion layer to make comparison, and the relative importance of any two factors to be quantitatively assigned. This paper use the data obtained from the questionnaire to construct comparison judgment matrix. If the score rate of a target is higher, then the impact of this index is higher, as shown in Table 1. 
Table 1. Standard Degree of the Judgment Matrix

\begin{tabular}{|c|c|}
\hline Description & Value \\
\hline Two indicators compared to the same degree of importance & 1 \\
\hline Two indicators compared to an indicator is a little more important than another & 3 \\
\hline Two indicators compared to an indicator is significantly more important than another & 5 \\
\hline Two indicators compared to an indicator is very important than another & 7 \\
\hline Two indicators, an indicator than the other indicators of extreme importance & 9 \\
\hline
\end{tabular}

Based on the above rules, the judgment matrix $A_{i j}, A_{i j}=1 / A_{j i}, A_{i i}=1$. In the process of determining the value of $A_{i i}$, using the method of multiple polling, consult the experts according to table 1 scale comparison method $A_{i j}$, which is $V_{i}$ with respect to the importance of the $V j$ factors, two factors are between the relative importance value of the scale, the experts give statistics, to determine the final value by using Delphy method. According to $A_{i j}$, can get the weight coefficient of evaluation index of $W_{l}, W_{2}, \ldots, W_{n}$.

$$
W_{i}=\frac{A_{i}}{\sum A_{i}}, A_{i}=\sqrt[n]{a_{i 1} \times a_{i 2} \times \cdots \times a_{i 12}}
$$

It is impossible to make a complete comparison of the $\mathrm{n}$ factors, so a consistency index $\mathrm{CR}$ is proposed. When $\mathrm{CR}=<0.1$, the judgment matrix $\mathrm{A} i j$ is with good consistency.

$$
C R=\frac{C_{i}}{R_{i}}
$$

3) Index weight of learning scoring model. By the analytic hierarchical analysis, determines the weight of criterion layer index and weight of index layer index factors, finally through sort level indicators to determine the final weights.

Through the analytic hierarchy process, the weight of the index factors and the weight of the index factors are determined, as shown in Table 2. Sort level is aimed at the top, along the hierarchy top-down computed layer by layer can be computed the lowest layer to the relative importance of the top index ranking values of that sort level. Total sort $W$ is equal to the weight of the index weight of this layer $W_{i j}$ times with the corresponding upper level index weight $W_{i}$. 
Table 2. Index weight of learning scoring model

\begin{tabular}{cccc}
\hline Target layer & First layer index & Second layer index & Weight \\
\hline \multirow{3}{*}{ Learing foundation } & Course content & 0.052 \\
& & Course form & 0.146 \\
& & Instructional design & 0.028 \\
& Learning outcomes & Multimedia application value & 0.050 \\
Learning Scoring & & Knowledge development & 0.295 \\
& & Learning type & 0.022 \\
& & Learning resource sharing & 0.021 \\
& & Interactive function & 0.173 \\
& Learning process & Learning convenience & 0.057 \\
& & Learning navigation & 0.015 \\
& & Supporting teaching resources & 0.028 \\
\hline
\end{tabular}

Vector $W$ is defined as the weight vector: $W=w_{i}$. A total of $N$ questionnaires were collected, and the evaluation matrix: $U=u_{i j}$, the $i$ value ranged from 1 to 12 , the $j$ value was in the range of 1 to $5, u_{i j}$ indicated that the evaluation factor $a_{i}$ on the evaluation of the standard component $b_{j}$ membership. Then the model use $W$ and $U$ to compute the score matrix $S$ :

$$
S=W \times U
$$

The score is the final score of the quality of the course, according to the total score to determine the level of evaluation of curriculum quality.

\section{Data Statistics and Analysis}

The sampling survey of the quality and effect of the course is the original data collection and classification of the teaching evaluation, which has a very important influence on the scores. Questionnaire design, random sampling survey and data statistics are the key to the comprehensive evaluation of learning quality and effect. 100 questionnaires were distributed in the sample survey, and a total of 86 questionnaires were collected, and the 82 valid questionnaires were collected. The effective recovery rate was $95 \%$.

According to the questionnaire survey and statistics, the evaluation matrix $U$ is composed of 12 evaluation index elements corresponding to the evaluation of the standard B statistical results, the total number of questionnaires to 93 valid questionnaires as the base. 


$V=\left[\begin{array}{ccccc}39.6 & 33.4 & 8.2 & 0.4 & 0 \\ 40.2 & 30.2 & 9.8 & 1.4 & 0 \\ 28.4 & 32.2 & 18.6 & 2.4 & 0 \\ 29.2 & 34 & 15.4 & 3 & 0 \\ 33.4 & 28 & 16.6 & 3.6 & 0 \\ 27.8 & 31.4 & 18.8 & 3.6 & 0 \\ 38.4 & 28.2 & 13.2 & 1.8 & 0 \\ 36.8 & 30.2 & 12.2 & 2.4 & 0 \\ 35 & 32.6 & 12.6 & 1.4 & 0 \\ 34 & 35.2 & 11 & 1.4 & 0 \\ 27.2 & 42.6 & 9.8 & 2 & 0 \\ 24.2 & 44.4 & 11.4 & 1.6 & 0\end{array}\right]$

According to the evaluation standard, the grade of the course is 87 , which shows that the learning quality and effect score of the public security information management course is good, but it has not yet reached the best.

\section{Discussion and Future Work}

Analysis to determine the weight coefficient of qualitative research is more obvious than the reasonable public security information management course this scoring model using AHP, the comprehensive evaluation method of combining the evaluation results more reliable, more operational. In the same survey conclusion under the premise, using the analytic hierarchy process improves the accuracy of network course comprehensive evaluation model, the validity and reliability of the evaluation index system of setting evaluation has been improved to a certain extent.

This study takes the police information management course as the research object, constructs the learning evaluation index system using the method of literature analysis and investigation method and the analytic hierarchy process, to improve the curriculum construction, and optimizes the network has certain guiding significance to the quality of network education. However, due to the construction of learning evaluation index system is a more complex and interdisciplinary research work, so this study still needs to further improve the evaluation index system.

\section{Acknowledgment}

This author's work is supported by JiangXi Research on teaching reform of higher education (JXJG-15-19-3), JiangXi Science and technology research project of Education Department (GJJ151193), JiangXi Social Science Planning Projects during the 12th FiveYear Plan(14TQ05), JiangXi University Party Building Project(16DJQN065) and JiangXi Police College Scientific Research Project(2016JGZB008). 


\section{References}

[1] Wang QiFang. Construction of Network Teaching Quality Evaluation[J]. Heilongjiang Higher Education Research, 2005, (10): 92-93. (in Chinese)

[2] Lin Huimin, Wan Daihong. Effective Learning Under Information Environment[M]. Beijing: Beijing Normal University press, 2012. (in Chinese)

[3] Fu Gangshan. Study on the construction of evaluation index system of effective learning in network environment[J]. Audio Visual Education Research, 2016,08:23-30. (in Chinese)

[4] Zhao Jianbao. Construction of evaluation index system of higher vocational ability course [J]. Vocational and Technical Education, 2010,34:51-54. (in Chinese)

[5] Zhang Cuiling. The evaluation model of students' learning under the background of quality education [J]. Journal of Taiyuan Normal University, 2015,03:93-96. (in Chinese)

[6] Qian Xiaoxian. AHP based network learning evaluation model[J]. Information Research, 2013,05:72-75. (in Chinese)

[7] Su Xin. A group decision making model for students' learning evaluation in mathematics[J]. Journal of Beijing Institute of Petrochemical Technology, 2011,02:58-60. (in Chinese)

[8] Yang Yujie. Construction of mobile agent network evaluation model based on learning[J]. Science and Technology Innovation, 2010,10:35-36.. (in Chinese)

[9] Zhang Ping. Study on evaluation model of collaborative learning in network environment[J]. Science and Technology Information Development and Economy, 2010,34:101-103. (in Chinese)

[10] Chen Lihua. Research on student learning evaluation model based on Bayesian network[J]. Science and Technology Information, 2009,08:374-375. (in Chinese) 